\title{
Mechanism of Action of Ulipristal Acetate for Emergency Contraception: A Systematic Review
}

\author{
Elena Rosato*, Manuela Farris and Carlo Bastianelli \\ Department of Gynecological and Obstetrical Sciences and Urological Sciences, "Sapienza" University of Rome, Rome, Italy
}

\section{OPEN ACCESS}

Edited by:

Cesare Mancuso,

Catholic University School

of Medicine, Italy

Reviewed by:

Robert Nistico,

University of Calabria, Italy

Fiorella Miceli,

Catholic University School

of Medicine, Italy

*Correspondence:

Elena Rosato

e.rosato@hotmail.it

Specialty section:

This article was submitted to

Experimental Pharmacology and Drug

Discovery,

a section of the journal

Frontiers in Pharmacology

Received: 21 November 2015

Accepted: 22 December 2015

Published: 12 January 2016

Citation:

Rosato E, Farris M and Bastianelli C (2016) Mechanism of Action

of Ulipristal Acetate for Emergency

Contraception: A Systematic Review.

Front. Pharmacol. 6:315.

doi: 10.3389/fphar.2015.00315
Ulipristal acetate (UPA) is now recommended as first choice hormonal emergency contraception (EC), due to its higher efficacy and similar safety compared to Levonorgestrel - EC. Even though all trials demonstrated that the first mechanism of action is inhibition of ovulation, some authors still postulate that a post fertilization effect is also possible, raising the alert on medication and fostering the ethical debate. A Medline database search was performed in order to find recent articles related to UPA's effects on ovulation, on fallopian tube and on endometrium. We also analyzed the effects on sperm function and pregnancy. All studies conclude that UPA is effective in inhibition of ovulation even when administered shortly before LH peak. The effects on fallopian tube are unclear: according to some authors UPA inhibits ciliar beat through an agonistic effect on progesterone receptors, according to others it antagonizes the progesterone-induced ciliar beat decrease. Concerning the action on endometrium and on embryo implantation most of the studies concluded that low dose UPA used for EC has no significant effect on the decrease of endometrial thickness and on embryo's attachment, but these results are still matter of debate. Finally recent evidence suggests that UPA modulates human sperm functions while it has no effect on established pregnancy. To date the majority of the evidence concurs in excluding a post-fertilization effect of UPA, even though more studies are needed to clarify its mechanism of action.

Keywords: ulipristal acetate, emergency contraception, ovulation, endometrium, embryo implantation, fallopian tube

\section{INTRODUCTION}

To date, three hormonal methods and the use of a copper intrauterine device are available worldwide for emergency contraception (EC), while the use of a fourth hormonal method (low dose mifepristone 10-25 mg) is available only in Armenia, China, Russia, and Vietnam.

First available hormonal EC pills were based on existing combined oral contraceptives preparations, containing ethinyl estradiol (EE) and levonorgestrel (LNG) administered according the so-called Yuzpe regimen (Yuzpe et al., 1974).

Then, it has been shown that the LNG at the dose of $1,5 \mathrm{mg}$ alone was both more effective and better tolerated than the Yuzpe regimen (WHO, 1998).

The World Health Organization (WHO, 1999) pioneered also the trials for using a selective progesterone receptor modulator (SPRM) for EC. These trials led to the development of a second generation SPRM, ulipristal acetate (UPA) at the dose of $30 \mathrm{mg}$. Use of this SPRM for EC was 
authorized by the European Medicines since 2009 in Europe (EMEA, 2009) and by the US Food and Drug Administration (FDA) in 2010 and in Asia (US FDA, 2010).

Ulipristal acetate is now recommended as first line treatment for EC, due to its higher efficacy and a similar rate of side effects when compared to LNG-EC.

The exact pharmacological mechanism of action of UPA is still under debate. Even though there is good evidence that the main mechanism of action is inhibition of ovulation, whereas a post-fertilization effect has not been shown, some still consider the latter also possible, raising the alert on medication and fostering the ethical debate because some religious views consider fertilization the initial event of human life.

Aim of this review is to collect experimental and clinical evidence regarding the effects of UPA both before and post fertilization, in order to refine the ethical debate.

This article reviews UPA's mechanism of action mainly on preventing ovulation, on interfering with oocyte or zygote transport through fallopian tube, and on endometrium receptivity and embryo implantation. The effects of UPA on sperm function and pregnancy were also analyzed (Table 1).

\section{PHARMACOKINETICS AND PHARMACODYNAMICS}

Ulipristal acetate is a derivative of 19-norprogesterone. The halflife after oral intake is $32 \mathrm{~h}$; it binds to plasma proteins for 97-99\%, and it is metabolized by the citochrome P450 (GemzellDanielsson et al., 2013a).

Ulipristal acetate depending on the location, the presence of coactivators or coinhibitors of gene expression, and the serum levels of progesterone may exert actions of an agonist or antagonist of progesterone.

The binding capacity to glucocorticoid and androgen receptors is lower than its antiprogestin activity: UPA shows in vivo antiglucocorticoid and antiandrogen activity only at doses 50-fold higher than those needed for antiprogestin effect (Gemzell-Danielsson and Meng, 2010).

\section{EFFECTS ON OVULATION}

In the follicular phase of menstrual cycle the gonadotropins (LH e FSH) levels increase. FSH promotes the differentiation of primary follicle to secondary follicle and acts on the granulosa cells stimulating them to convert testosterone into estradiol (E2), which is released to support the follicle's growth.

In the pre-ovulatory phase estradiol levels increase and stimulate hypothalamus resulting an increased secretion of LH. In particular estrogens exert a positive feedback stimulating de novo progesterone synthesis within the hypothalamus to trigger the LH surge (Micevych and Sinchak, 2011). The LH surge acts on theca cells by stimulating the proteolytic activity resulting in follicular rupture. Ovulation typically occurs 13 to $16 \mathrm{~h}$ after the LH peak and 24-26 h after the estradiol peak. The short fertile window typically begins 5 days before, through ovulation, and concludes 1 day after ovulation.

In the initial phases of clinical development (phase I and II) two studies analyzed various pharmacodynamic effects of UPA (kwon as CDB-2914) on ovulation blockade, at different stages of the follicular phase.

When administered in mid follicular phase it has been shown that a single dose of 10-50-100 mg of UPA, with a follicle's diameter of 14-16 mm, causes a dose-dependent delay in the time interval from treatment to follicular rupture and a suppression of E2. At higher doses, the lead follicle stopped it's grow and was replaced by a new lead follicle (Stratton et al., 2000).

On the other hand, if administered when the size of the leading follicle was $\geq 18 \mathrm{~mm}$, follicular rupture failed to occur within 5 to 6 days following treatment in $59 \%$ of cycles. The block/delay ovulation occurred in $100 \%$ of women with very low LH levels, and in $79 \%$ of women with increasing LH levels. The ovulation's blockade has not occurred in the group of women where LH was at its peak (Brache et al., 2010).

Compared to LNG there are significant differences. An early study (Croxatto et al., 2004) demonstrated that when the follicle reaches $18-20 \mathrm{~mm}$, ovulation is prevented by LNG in only $12 \%$ of cycles (compared with 13\% in the placebo group). More recently (Brache et al., 2013), it was shown that, at the time of the LH surge, UPA is more effective than LNG and placebo (UPA 79\%, LNG $14 \%$, and placebo $10 \%$ ).

This demonstrates that UPA is effective even when administered shortly before ovulation, when the LH surge has started, a time period when LNG-CE is no longer effective (Jamin, 2015).

The ability of UPA to inhibit ovulation even when it is given just before ovulation is crucial because the probability of conception is the highest (Wilcox et al., 2004) and is due to the particular properties of this SPRM: when progesterone levels are low it acts as an agonist compound, but when they rise, it behaves as an antagonist by blocking the ascent of LH and therefore the ovulatory peak. UPA treatment prevents ovulation presumably by repressing expression of PR-dependent genes critical for ovulation (Nallasamy et al., 2013). When the LH reaches its peak it becomes insensitive to the progesterone's feedback and to UPA.

This antagonist effect of UPA on PR, has been confirmed by a recent study (Brache et al., 2015) suggesting that initiating desogestrel (DSG) treatment the day after UPA significantly reduced the ovulation delaying effect of UPA.

\section{EFFECTS ON THE FALLOPIAN TUBE}

The fallopian tube plays an important role in human conception. Fertilization normally occurs in the ampullary region of the tube within $24 \mathrm{~h}$ after ovulation. Both muscular contractions and cilia activity in the human fallopian tube are involved in the transportation of zygote.

Too rapid or too slow zygote's tubal transport could cause desynchronization between the zygote itself and the fallopian tube, and/or the blastocyst and the endometrium. 


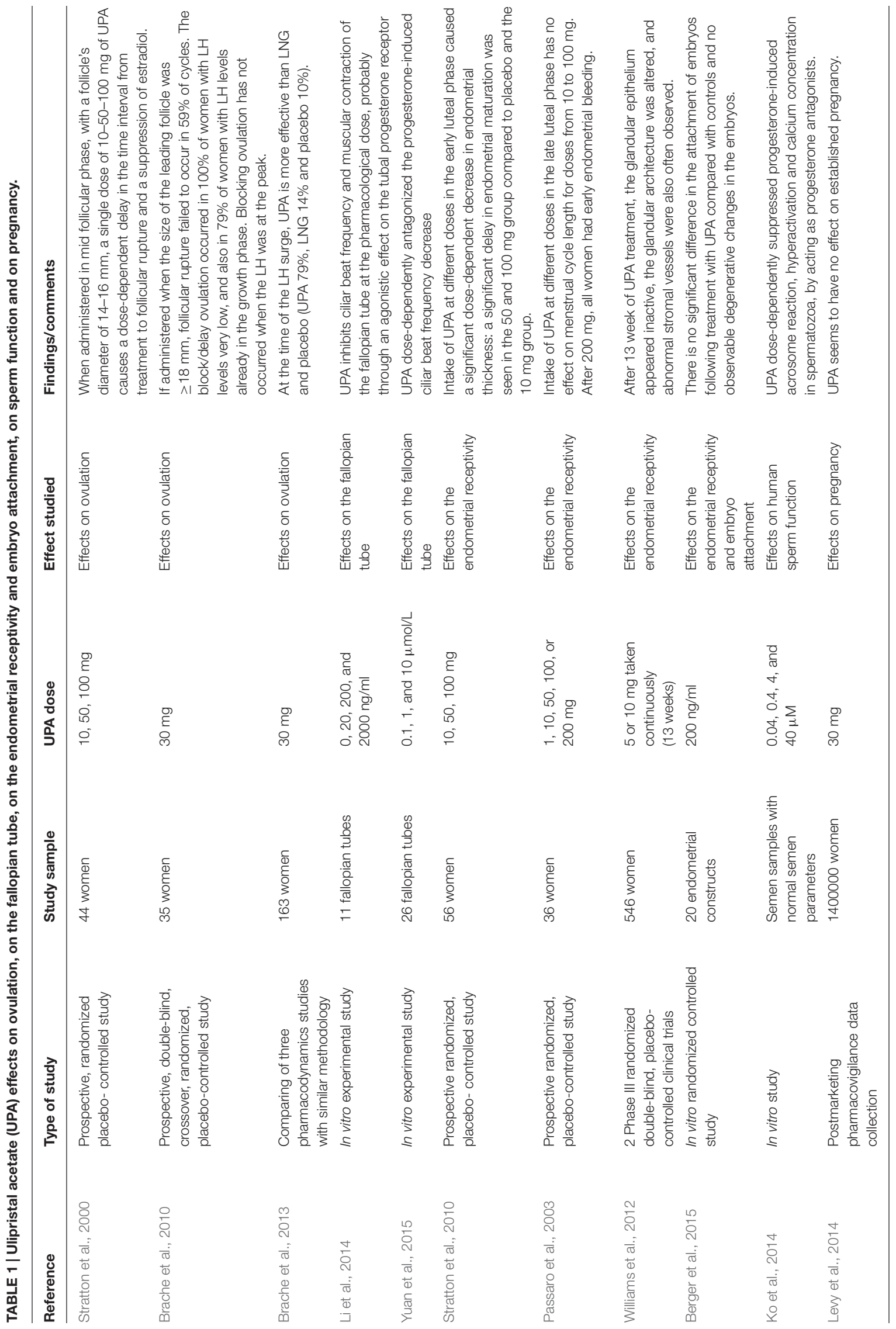


Some studies have suggested that progesterone may suppress ciliary beating frequency $(\mathrm{CBF})$ and muscular contraction in the fallopian tube: cilia beat significantly slower after treatment with high doses of progesterone (Wanggren et al., 2008). Similar results were shown by a recent study indicating that LNG decreases the CBF in vitro and in vivo (Zhao et al., 2015).

The action of the UPA on the fallopian tube has been investigated in two recent in vitro studies.

In the first study (Li et al., 2014), authors demonstrate that UPA inhibits CBF and muscular contraction of the fallopian tube at the pharmacological dose, probably through an agonistic effect on the tubal PR. Based on these results, the authors postulated that UPA:

- exerts an agonistic effect on PR in the fallopian tube on the PRA isoform, but partial agonist/antagonist activity on the PR-B isoform (Leo and Lin, 2008). It has also been hypothesized, as shown in mouse model, an agonistic action of UPA in the fallopian tube in contrast to the antagonistic action at the ovary (Teilmann et al., 2006).

- up-regulates mRNA expression of the PR (both generic and specific to PR-B).

- down-regulates andrenomedullin, which plays an important role in enhancing the $\mathrm{CBF}$ and muscle contraction tone, amplitude, and frequency in fallopian tube (Li et al., 2010).

According to these finding, UPA should increase the risk of ectopic pregnancy, inhibiting tubal function. In contrast to this, no evidence has been shown an increased risk of ectopic pregnancy with the use of UPA for EC (Levy et al., 2014). It should be stressed that the development of an ectopic pregnancy may not be solely explained by delayed embryo transport, but has to be accompanied by an altered tubal environment and/or embryo factors to result in tubal implantation (Shaw et al., 2010).

In contrast Yuan et al. (2015) showed that UPA does not directly affect $\mathrm{CBF}$ or the ultrastructure of the cilia, but it dose-dependently antagonized the progesterone-induced $\mathrm{CBF}$ decrease. To prove the hypothesis of a progesterone antagonist action the authors highlighted that: Mifepristone, an antagonist of the $\mathrm{PR}$, inhibits progesterone-induced $\mathrm{CBF}$ reduction (Mahmood et al., 1998); UPA has been shown to be a progesterone antagonistic without agonistic activity in most studied published (Attardi et al., 2002; Chabbert-Buffet et al., 2005; Xu et al., 2008; Communal et al., 2012; Ko et al., 2014) and finally, their study demonstrates that UPA is able to up-regulate the expression levels of the estrogen receptor (ER) and the PR in the fallopian tubes, while progesterone down regulates them (Horne et al., 2009).

\section{EFFECTS ON ENDOMETRIAL RECEPTIVITY AND EMBRYO ATTACHMENT}

During the luteal phase, the corpus luteum stimulates the production of progesterone which creates favorable conditions for the implantation of the fertilized egg in the endometrium, consisting in accumulation of glycogen and lipid granules in the cytoplasm of stromal cells (decidual transformation).

While the effects of UPA on ovulation are well recognized, the controversy arises on its action on endometrium receptivity, in contrast with LNG, on which there is a unanimous opinion in believing that it has no effect on implantation (Lalitkumar et al., 2007; Meng et al., 2009; Palomino et al., 2010).

When in her pre-ovulatory study Brache reported that the effects of UPA at the LH peak are null (Brache et al., 2010), some authors (Mozzanega et al., 2013) pointed out that, if UPA has no effect on the LH peak, it should not have any effects two days before ovulation, in contradiction with the conclusive statement of the paper and therefore the very high UPA's effectiveness in preventing pregnancies which does not decrease with the time elapsed from unprotected intercourse (Fine et al., 2010; Glasier et al., 2010) should be explained by a post-fertilization effect.

There are two major early clinical phase studies on the postovulatory effects of UPA.

In the first (Stratton et al., 2010), the authors comparing early luteal phase treatment with placebo, 10, 50, $100 \mathrm{mg}$ unmicronized UPA showed that UPA caused a significant dosedependent decrease in endometrial thickness: a significant delay in endometrial maturation was seen in the 50 and $100 \mathrm{mg}$ group compared to placebo and the $10 \mathrm{mg}$ group upon biopsy four to 6 days after ovulation.

On the basis of these results, (Gemzell-Danielsson et al., 2013a,b, 2014) in several subsequent reviews concludes that low dose UPA (30 mg) as used for EC has no significant effect on endometrium.

Some authors (Glasier et al., 2010; Hillemanns and Hepp, 2013; Mozzanega et al., 2013) confuted that the $50 \mathrm{mg}$ UPA tablet used in the early luteal phase study involves a significant reduction in endometrial thickness, and it is pharmacokinetically identical to the $30 \mathrm{mg}$ micronized formulation used in the EC.

The second luteal phase study (Passaro et al., 2003) shows that intake of UPA at different doses in the late luteal phase has no effect on menstrual cycle length for doses from 10 to $100 \mathrm{mg}$.

More recently, a study of the endometrial morphology with UPA taken continuously (13 weeks) at lower doses (5 or $10 \mathrm{mg}$ ), was carried out in a group of patients with uterine myomas (Williams et al., 2012). Following treatment, the glandular epithelium appeared inactive, the glandular architecture was altered and abnormal stromal vessels were also often observed (the so called PRM-associated endometrial changes PAEC).

In a similar study (Donnez et al., 2012), at 13 weeks of treatment with different doses of UPA the mean endometrial thicknesses was $9.4 \mathrm{~mm}$ in the group receiving $5 \mathrm{mg}$ and $10.7 \mathrm{~mm}$ in the group receiving $10 \mathrm{mg}$. The PAEC were observed in the same percentage of women receiving $5 \mathrm{mg}$ or $10 \mathrm{mg}$ UPA.

Finally, the effect of UPA on human implantation has been extensively studied utilizing an in vitro three-dimensional endometrial model. With this in vitro model, it was shown (Berger et al., 2015) that there is no significant difference in the attachment of embryos following treatment with UPA compared with controls and no observable degenerative changes in the 
embryos. Moreover it was found that the level of genes of several factors believed to be vital for embryo implantation remain unaltered in the endometrial construct after exposure to UPA.

\section{EFFECTS ON HUMAN SPERM FUNCTION}

In their transit in female reproductive tract, spermatozoa are exposed to increased levels of progesterone secreted by the cumulus cells and the corpus luteum. Progesterone in human follicular fluid is essential for acrosome reaction induction, permitting calcium influx into spermatozoa.

Initially (Munuce et al., 2012) it was reported that UPA does not modify sperm capacitation, nor induce acrosome reaction (no agonist effect on PR) or prevent human follicular fluid induced acrosomal reaction (no antagonist effect on PR).

A more recent study (Ko et al., 2014) has shown that UPA dose-dependently suppressed progesterone-induced acrosome reaction, hyperactivation, and calcium concentration in spermatozoa, concluding that UPA modulate human sperm functions by acting as progesterone antagonists.

In contrast to UPA, in vitro (Brito et al., 2005) and in vivo (Do Nascimento et al., 2007) studies found that LNG at doses used for EC has no direct effect on sperm function.

\section{EFFECTS ON PREGNANCY}

In a post marketing experience on more than 1 million women (Levy et al., 2014) 376 pregnancies have been observed. Of the 232 with a known outcome, 28 ended with live births, 34 were miscarriages, 151 induced abortions, 4 ectopic pregnancies, and 15 which are still ongoing.

The observed rate of miscarriages and ectopic pregnancy were not increased when compared with the rate observed in the general population.

\section{DISCUSSION AND CONCLUSION}

Several studies provide strong direct evidence that both UPA and LNG act by preventing or delaying ovulation. The difference between the effects of UPA and LNG on ovulation is in their window of action. When the follicular size is $>18 \mathrm{~mm}$, LNG is unable to prevent ovulation while UPA acts until before the LH peak immediately before ovulation (Brache et al., 2013).

Those that advocate a post fertilization effect of UPA stress that its effectiveness in preventing pregnancies is very high, although it is taken in proximity of ovulation. On this regard, some key points need to be considered.

Firstly, the published articles on the postovulatory effects UPA rely on already published studies and not on new in vitro/vivo studies. Moreover in many of these debates, there is not a clear distinction between the time of ovulation and the time of sexual intercourse. The " 5 days after" refers to sexual intercourse event and not to the time of ovulation. This could be considered as the same kind of miswording which referred to LNG-EC as "the day after" pill. On this subject, some authors (Hillemanns and Hepp, 2013) sustain that when unprotected intercourse occurs for example $12 \mathrm{~h}$ after ovulation and UPA is taken " 5 days later," then UPA must have other effects than delaying ovulation.

Secondly, in studies on UPA effects on the fallopian tube (Li et al., 2014; Yuan et al., 2015) is unclear how it affects fertilization and /or transport of the fertilized egg and therefore the embryo implantation.

Thirdly, the authors that showed an endometrial suppression after treatment with the same SPRM utilized for treatment of myomas (Williams et al., 2012) did not demonstrate that this is also true for the UPA dosage utilized for EC.

Finally, the abortifacient role of Mifepristone ("RU-486"), at higher doses, could influence negatively the attitude toward same family compounds. The drug is approved for use in combination with misoprostol in a number of countries to terminate a pregnancy, given at the dose of 200-600 mg which is 8- to 60-fold greater than the dose used for EC (WHO, 2012).

On the other hand, it should be pointed out that the exact mechanism of action of UPA is not completely clarified. In particular it is still poorly understood when it acts as agonist or antagonist of progesterone. Knowledge of its precise mechanism of action would be helpful to better understand its effects on target organs.

If there would be a method of identifying fertilization, it could have been the only way to show if UPA acts in the early phase of the zygote, but attempts to identify a molecule that could operate as a early marker of fertilization have not be successful. In particular a protein called the "early pregnancy factor" (EPF) was first described in mice as an immunosuppressive agent (Morton et al., 1974) and subsequently identified in additional species and humans (Morton et al., 1982; Tinneberg et al., 1984). The biological features of EPF suggest an opportunity for early pregnancy diagnosis: it could be, in the future, a marker to verify UPA's mechanism of action (Hatzel et al., 2015).

The ethical problem arises in considering the possibility of its putative post fertilization effect, based on the assertion that it causes abortion.

By definition, contraception comprises all methods capable of preventing pregnancy as defined by the WHO. Accepting this definition, hormonal EC includes all methods acting after intercourse, but before implantation. To date, the mechanism of action appears rather related to postponing ovulation, having an effect on sperm function while no effect on endometrium has been shown at clinically relevant doses.

\section{AUTHOR CONTRIBUTIONS}

ER and MF wrote the articles, CB supervised the work. 


\section{REFERENCES}

Attardi, B. J., Burgenson, J., Hild, S. A., Reel, J. R., and Blye, R. P. (2002). CDB-. (4124) and its putative monodemethylated metabolite, CDB-4453, are potent antiprogestins with reduced ntiglucocorticoid activity: in vitro comparison to mifepristone and CDB-2914. Mol. Cell Endocrinol. 188, 111-123. doi: 10.1016/S0303-7207(01)00743-2

Berger, C., Boggavarapu, N. R., Menezes, J., Lalitkumar, P. G. L., and GemzellDanielsson, K. (2015). Effects of ulipristal acetate on human embryo attachment and endometrial cell gene expression in an in vitro co-culture system. Hum. Reprod. 30, 1-12. doi: 10.1093/humrep/dev030

Brache, V., Cochon, L., Deniaud, M., and Croxatto, H. B. (2013). Ulipristal acetate prevents ovulation more effectively than levonorgestrel: analysis of pooled data from three randomized trials of emergency contraception regimens. Contraception 88, 611-618. doi: 10.1016/j.contraception.2013.05.010

Brache, V., Cochon, L., Duijkers, I. J. M., Levy, D. P., Kapp, N., Monteil, C., et al. (2015). A prospective, randomized, pharmacodynamic study of quickstarting a desogestrel progestin-only pill following ulipristal acetate for emergency contraception. Hum. Reprod. 30, 2785-2793. doi: 10.1093/humrep/ $\operatorname{dev} 241$

Brache, V., Cochon, L., Jesam, C., Maldonado, R., Salvatierra, A. M., Levy, D. P., et al. (2010). Immediate pre-ovulatory administration of $30 \mathrm{mg}$ ulipristal acetate significantly delays follicular rupture. Hum. Reprod. 25, 2256-2263. doi: 10.1093/humrep/deq157

Brito, K. S., Bahamondes, L., Nascimento, J. A., de Santis, L., and Munuce, M. J. (2005). The in vitro effect of emergency contraception doses of levonorgestrel on the acrosome reaction of human spermatozoa. Contraception 72, 225-228. doi: 10.1016/j.contraception.2005.04.005

Chabbert-Buffet, N., Meduri, G., Bouchard, P., and Spitz, I. M. (2005). Selective progesterone receptor modulators and progesterone antagonists: mechanisms of action and clinical applications. Hum. Reprod. Update 11, 293-307. doi: 10.1093/humupd/dmi002

Communal, L., Vilasco, M., Hugon-Rodin, J., Courtin, A., Mourra, N., Lahlou, N., et al. (2012). Ulipristal acetate does not impact human normal breast tissue. Hum. Reprod. 27, 2785-2798. doi: 10.1093/humrep/des221

Croxatto, H. B., Brache, V., Pavez, M., Cochon, L., Forcelledo, M. L., Alvarez, F., et al. (2004). Pituitary-ovarian function following the standard levonorgestrel emergency contraceptive dose or a single 0.75 -mg dose given on the days preceding ovulation. Contraception 70, 442-450. doi: 10.1016/j.contraception.2004.05.007

Do Nascimento, J. A., Seppalla, M., Perdigao, A., Espejo-Arce, X., Munuce, M. J., Hautala, L., et al. (2007). In vivo assessment of the human sperm acrosome reaction and the expression of glycodeling-A in human endometrium after levonorgestrel-emergency contraceptive pill administration. Hum. Reprod. 22, 2190-2195. doi: 10.1093/humrep/dem119

Donnez, J., Tomaszewski, J., Vázquez, F., Bouchard, P., Lemieszczuk, B., Baró, F., et al. (2012). Ulipristal acetate versus leuprolide acetate for uterine fibroids. N. Engl. J. Med. 366, 421-432. doi: 10.1056/NEJMoa1 103180

EMEA (2009). European Medicines Agency. Available at: http://www. ema.europa.eu/docs/en_GB/document_library/EPAR_-_Public_assessment_ report/human/001027/WC500023673.pdf

Fine, P., Mathé, H., Ginde, S., Cullins, V., Morfesis, J., and Gainer, E. (2010). Ulipristal acetate taken 48-120 hours after intercourse for emergency contraception. Obstet. Gynecol. 115, 257-263. doi: 10.1097/AOG.0b013e3181c8e2aa

Gemzell-Danielsson, K., Berger, C., and Lalitkumar, P. G. (2014). Mechanisms of action of oral emergency contraception. Gynecol. Endocrinol. 30, 685-687. doi: 10.3109/09513590.2014.950648

Gemzell-Danielsson, K., Berger, C., and Lalitkumar, P. G. L. (2013a). Emergency contraception - mechanisms of action. Contraception 87, 300-308. doi: 10.1016/j.contraception.2012.08.021

Gemzell-Danielsson, K., Rabe, T., and Cheng, L. (2013b). Emergency contraception. Gynecol. Endocrinol. 29, 1-14. doi: 10.3109/09513590.2013. 774591

Gemzell-Danielsson, K., and Meng, C. X. (2010). Emergency contraception: potential role of ulipristal acetate. Int. J. Womens Health 2, 53-61. doi: 10.2147/IJWH.S5865
Glasier, A. F., Cameron, S. T., Fine, P. M., Logan, S. J., Casale, W., Van Horn, J., et al. (2010). Ulipristal acetate versus levonorgestrel for emergency contraception: a randomised non inferiority trial and meta-analysis. Lancet 375, 555-562. doi: 10.1016/S0140-6736(10)6010160108

Hatzel, J. N., Bouma, G. J., Cleys, E. R., Bemis, L. T., Ehrhart, E. J., and McCue, P. M. (2015). Identification of heat shock protein 10 within the equineembryo, endometrium, and maternal peripheral bloodmononuclear cells. Theriogenology 83, 832-839. doi: 10.1016/j.theriogenology.2014. 11.020

Hillemanns, P., and Hepp, H. (2013). Letter to the Editor: K. Gemzell-Danielsson et al. Emergency contraception - mechanisms of action. Contraception 87, 300-308. doi: 10.1016/j.contraception.2012.08.021

Horne, A. W., King, A. E., Shaw. E., McDonald, S. E., Williams, A. R., Saunders, P. T., et al. (2009). Attenuated sex steroid receptor expression in fallopian tube of women with ectopic pregnancy. J. Clin. Endocrinol. Metab. 94, 5146-5154. doi: $10.1210 /$ jc. $2009-1476$

Jamin, C. (2015). Emergency contraception: efficacy difference between levonorgestrel and ulipristal acetate depending on the follicular size at the time of an unprotected sexual Intercourse. Gynecol. Obstetr. Fert. 43, 242-247. doi: 10.1016/j.gyobfe.2015.01.010

Ko, J. K. Y., Huang, V. W., Li, R. H. W., Yeung, W. S. B., Ho, P. C., and Chiu P. C. N. (2014). An in vitro study of the effect of mifepristone and ulipristal acetate on human sperm functions. Andrology 2, 868-874. doi: 10.1111/j.20472927.2014.00261.x

Lalitkumar, P. G., Lalitkumar, S., Meng, C. X., Stavreus-Evers, A., Hambiliki, F., Bentin-Ley, U., et al. (2007). Mifepristone, but not levonorgestrel, inhibits human blastocyst attachment to an in vitro endometrial three-dimensional cell culture model. Hum. Reprod. 22, 3031-3037. doi: 10.1093/humrep/dem297

Leo, J. C. L., and Lin, V. C. L. (2008). The activities of progesterone receptor isoform $\mathrm{A}$ and $\mathrm{B}$ are differentially modulated by their ligands in a gene-selective manner. Int. J. Cancer 122, 230-243. doi: 10.1002/ijc.23081

Levy, D. P., Jager, M., Kapp, N., and Abitbol, J. L. (2014). Ulipristal acetate for emergency contraception: postmarketing experience after use by more than 1 million women. Contraception 89, 431-433. doi: 1016/j.contraception.2014. 01.003

Li, H. W. R., Liao, S. B., Chiu, P. C. N., Tam, W. W., Ho, J. C., Ng, E. H. Y., et al. (2010). Expression of adrenomedullin in human oviduct, its regulation by the hormonal cycle and contact with spermatozoa, and its effect on ciliary beat frequency of the oviductal epithelium. J. Clin. Endocrinol. Metab. 95, E18-E25. doi: 10.1210/jc.2010-0273

Li, H. W., Liao, S. B., Yeung, W. S., Ng, E. H., O, W. S., and Ho, P. C. (2014). Ulipristal acetate resembles mifepristone in modulating human Fallopian tube function. Hum. Reprod. 29, 2156-2162. doi: 10.1093/humrep/deu210

Mahmood, T., Saridogan, E., Smutna, S., Habib, A. M., and Djahanbakhch, O. (1998). The effect of ovarian steroids on epithelial ciliary beat frequency in the human Fallopian tube. Hum. Reprod. 13, 2991-2994. doi: 10.1093/humrep/13.11.2991

Meng, C. X., Andersson, K., Bentin-Ley, U., Gemzell-Danielsson, K., and Lalitkumar, P. G. (2009). Effect of levonorgestrel and mifepristone on endometrial receptivity markers in a three-dimensional human endometrial cell culture model. Fertil. Steril. 91, 256-264. doi: 10.1016/j.fertnstert.2007.11.007

Micevych, P., and Sinchak, K. (2011). The Neurosteroid Progesterone Underlies Estrogen Positive Feedback of the LH Surge. Front. Endocrinol. 2:90. doi: 10.3389/fendo.2011.00090

Morton, H., Hegh, V., and Clunie, G. (1974). Immunosuppression detected in pregnant mice by rosette inhibition test. Nature 249, 459-460. doi: 10.1038/249459a0

Morton, H., Tinneberg, H. R., Rolfe, B., Wolf, M., and Mettler, L. (1982). Rosette inhibition test: a multicentre investigation of early pregnancy factor in humans. J. Reprod. Immunol. 4, 251-261. doi: 10.1016/0165-0378(82)90001-8

Mozzanega, B., Cosmi, E., and Battista Nardelli, G. (2013). Ulipristal acetate in emergency contraception: mechanism of action. Trends Pharmacol. Sci. 34, 195-196. doi: 10.1016/j.tips.2013.02.003

Munuce, M. J., Zumoffen, C., Cicaré, J., Caille, A., Ghersevich, S., and Bahamondes, L. (2012). Effect of exposure to ulipristal acetate on sperm function. Eur. J. Contracept. Reprod. Health Care 17, 428-437. doi: $10.3109 / 13625187.2012 .725877$ 
Nallasamy, S., Kim, J., Sitruk-Ware, R., Bagchi, M., and Bagchi, I. (2013). Ulipristal blocks ovulation by inhibiting progesterone receptor- ependent pathways intrinsic to the ovary. Reprod. Sci. 20, 371-381. doi: 10.1177/1933719112459239

Palomino, W., Kohen, P., and Devoto, L. (2010). A single midcycle dose of levonorgestrel similar to emergency contraceptive does not alter the expression of the L-selectin ligand or molecular markers of endometrial receptivity. Fertil. Steril. 94, 1589-1594. doi: 10.1016/j.fertnstert.2009.09.013

Passaro, M. D., Piquion, J., Mullen, N., Sutherland, D., Zhai, S., Figg, W. D., et al. (2003). Luteal phase dose-response relationships of the antiprogestin CDB-2914 in normally cycling women. Hum. Reprod. 18, 1820-1827. doi: 10.1093/humrep/deg342

Shaw, J. L., Dey, S. K., Critchley, H. O., and Horne, A. W. (2010). Current knowledge of the aetiology of human tubal ectopic pregnancy. Hum. Reprod. Update 16, 432-444. doi: 10.1093/humupd/dmp057

Stratton, P., Hartog, B., Hajizadeh, N., Piquion, J., Sutherland, D., Merino, M., et al. (2000). A single mid-follicular dose of CDB-2914, a new antiprogestin, inhibits folliculogenesis and endometrial differentiation in normally cycling women. Hum. Reprod. 15, 1092-1099. doi: 10.1093/humrep/15.5.1092

Stratton, P., Levens, E. D., Hartog, B., Piquion, J., Wei, Q., Merino, M., et al. (2010). Endometrial effects of a single early luteal dose of the selective progesterone receptor modulator CDB-2914. Fertil. Steril. 93, 2035-2041. doi: 10.1016/j.fertnstert.2008.12.057

Teilmann, S. C., Clement, C. A., Thorup, J., Byskov, A. G., and Christensen, S. T. (2006). Expression and localization of the progesterone receptor in mouse and human reproductive organs. J. Endocrinol. 191, 525-535. doi: 10.1677/joe.1.06565

Tinneberg, H. R., Staves, R. P., and Semm, K. (1984). Improvement of the rosette inhibition assay for the detection of early pregnancy factor in humans using the monoclonal antibody, anti-human-Lyt-3. Am. J. Reprod. Immunol. 5, 151-156. doi: 10.1111/j.1600-0897.1984.tb00187.x

US FDA (2010). Food and Drug Administration. Available at: http:// www.fda.gov/NewsEvents/Newsroom/PressAnnouncements/ucm222428.htm

Wanggren, K., Stavreus-Evers, A., Olsson, C., Andersson, E., and GemzellDanielsson, K. (2008). Regulation of muscular contractions in the human Fallopian tube through prostaglandins and progestogens. Hum. Reprod. 23, 2359-2368. doi: 10.1093/humrep/den260

Wilcox, A. J., Baird, D. D., Dunson, D. B., McConnaughey, D. R., Kesner, J. S., and Weinberg, C. R. (2004). On the frequency of intercourse around ovulation; evidence for biological infl uences. Hum. Reprod. 19, 1539-1543. doi: 10.1093/humrep/deh305
Williams, A. R., Bergeron, C., Barlow, D. H., and Ferenczy, A. (2012). Endometrial morphology after treatment of uterine fibroids with the selective progesterone receptor modulator, ulipristal acetate. Int. J. Gynecol. Pathol. 31, 556-569. doi: 10.1097/PGP.0b013e318251035b

World Health Organization [WHO] (1998). Task force on post-ovulatory methods for fertility regulation. randomized controlled trial of levonorgestrel versus the yuzpe regimen of combined oral contraceptives for emergency contraception. Lancet 352, 428-433. doi: 10.1016/S0140-6736(98) 05145-9

World Health Organization [WHO] (1999). Task force on post-ovulatory methods for fertility regulation. comparison of three single doses of mifepristone as emergency contraception: a randomized trial. Lancet 353, 697-702. doi: 10.1016/S0140-6736(98)07190-6

World Health Organization [WHO] (2012). Safe Abortion: Technical and Policy Guidance for Health Systems, 2nd Edn. Geneva: World Health Organization.

Xu, Q., Ohara, N., Liu, J., Amano, M., Sitruk-Ware, R., Yoshida, S., et al. (2008). Progesterone receptor modulator CDB-2914 induces extracellular matrix metalloproteinase inducer in cultured human uterine leiomyoma cells. Mol. Hum. Reprod. 14, 181-191. doi: 10.1093/molehr/gan004

Yuan, J., Zhao, W., Yan, M., Zhu, Q., Qin, G., Qiu, J., et al. (2015). Ulipristal Acetate antagonizes the inhibitory effect of progesterone on ciliary beat frequency and upregulates steroid expression levels in human Fallopian Tubes. Reprod. Sci. 22, 1516-1523. doi: 10.1177/1933719115589409

Yuzpe, A. A., Turlow, H. J., Ramzy, I., and Leyson, J. I. (1974). Post-coital contraception-A pilot study. J. Reprod. Med. 13, 53-58.

Zhao, W., Zhu, Q., Yan, M., Li, C., Yuan, J., Qin, G., et al. (2015). Levonorgestrel decreases cilia beat frequency of human fallopian tubes and rat oviducts without changing morphological structure. Clin. Exp. Pharmacol. Physiol. 42, 171-178. doi: $10.1111 / 1440-1681.12337$

Conflict of Interest Statement: The authors declare that the research was conducted in the absence of any commercial or financial relationships that could be construed as a potential conflict of interest.

Copyright (C) 2016 Rosato, Farris and Bastianelli. This is an open-access article distributed under the terms of the Creative Commons Attribution License (CC BY). The use, distribution or reproduction in other forums is permitted, provided the original author(s) or licensor are credited and that the original publication in this journal is cited, in accordance with accepted academic practice. No use, distribution or reproduction is permitted which does not comply with these terms. 